\title{
A Numerical Exploration of Engine Combustion Using Toluene Reference Fuel and Hydrogen Mixtures
}

\author{
Alessio Barbato ${ }^{1, *}$, Valentina Pessina ${ }^{1,}$ Massimo Borghi ${ }^{1}$ \\ ${ }^{1}$ Department of Engineering "Enzo Ferrari”, University of Modena and Reggio Emilia, Modena \\ 41125 , Italy
}

\begin{abstract}
Hydrogen-fueled internal combustion engines (H2ICEs) are capable of operating over a wide range of equivalence ratios: from ultralean mode to stoichiometric conditions. However, they provide maximum thermal efficiency and minimum NOx emissions if operated lean. Although NOx is produced, H2ICEs generate little or no $\mathrm{CO}, \mathrm{CO} 2, \mathrm{SO} 2$, $\mathrm{HC}$, or PM emissions. The main limitation to pure hydrogen fueling is power density. To overcome such an issue, mixtures of gasoline and hydrogen can be exploited, with small modifications to the engine feeding system. Due to the peculiar characteristics of hydrogen (in terms of thermophysical properties, molecular weight and propagating flame characteristics) care must be adopted when trying to address combustion using computational fluid dynamics (CFD) tools. In this work, we simulate the combustion of mixtures of toluene reference fuel (TRF) and hydrogen under largely different ratios. To simplify the problem, liquid and gaseous injections are neglected, and a premixed mixture at the inlet of the CFD domain is imposed. Due to the different laminar flame speeds of the mixture components, mass-fraction weighted in-house correlations based on chemical kinetics simulations are adopted. Outcomes are compared with those obtained using standard correlations and mixing rules available in most commercial CFD packages.
\end{abstract}

\section{Introduction}

The European Green Deal [1] sets out the European Union's (EU) path to climate neutrality by 2050 , through the deep decarbonization of all sectors of the economy; anthropogenic greenhouse gas (GHG) emission reductions are also set for 2030. This is not the first compact of the EU Commission aiming at the reduction of GHG emissions. Back in 2009, the EU imposed very challenging targets to strictly reduce GHG emissions with the Renewable Energy Directive [2] (RED). According to the European Parliament and Council [3], road transport accounted for $22 \%$ of the EU GHG emissions in 2015. For this reason, a Revised Renewable Energy Directive (REDII) [4] imposed that at least $10 \%$ of

\footnotetext{
* Corresponding author: alessio.barbato@unimore.it
} 
the energy used in transportation must be bio-based by 2020, and the overall EU target for Renewable Energy Sources consumption by 2030 has been raised to $32 \%$. The Commission's original proposal did not include a transport sub-target, which has been introduced by co-legislators in the final agreement: all Member States must require fuel suppliers to supply at least $14 \%$ of the energy consumed in road and rail transport by 2030 as renewable energy. Thus, in the last few years, biofuels have increasingly gained the attention of researchers in the automotive industry as a doable solution to cleaner powertrains, in compliance with EU regulations. Ethanol is the main biofuel currently used in production engines: besides being a renewable source of energy, it also has lower production costs compared to other alcohols, such as methanol or n-butanol $[5,6]$. Several experimental studies investigated the pure bio-alcohol fuels combustion characteristics in modern direct-injection spark-ignition engines (DISI). Irimescu et al. [7] compared stoichiometric butanol and ethanol mixtures in terms of combustion indicators and emissions in an optically accessible DISI research engine operated at full load. As shown by Di Iorio et al. [8], the addition of ethanol increases the octane number of the fuel, thus allowing an increase of the spark advances and/or a higher compression ratio. However, Sarathy et al. [9] highlighted that the addition of oxygenates led to a reduction of the massbased Lower Heating Value (LHV) of the fuel blend because fuel-oxygen atoms do not contribute to heat production; therefore, the reduction of the LHV is proportional to the mass percentage of oxygen. Hydrogen (H2) can be considered as a brighter fuel/additive to reduce internal combustion engines' (ICEs) emissions. As a matter of fact, H2ICEs have near-zero emissions levels and efficiencies higher than modern ICEs [10]. Furthermore, the well-to-wheel GHG reduction of H2ICE vehicles compared to hydrocarbon-fueled ones turns out to be positive [11]. H2 seems to be a feasible solution for current/future transportation, and H2ICEs could act as a bridging technology towards a widespread H2 infrastructure for alternative propulsion technologies such as fuel cells [12-14] since H2ICE vehicles can be operated also with conventional fuel.

The peculiar properties of $\mathrm{H} 2$ compared to both conventional liquid/gaseous fuels, such as gasoline and methane, make it a promising fuel for ICE applications, despite its low minimum ignition energy of $0.02 \mathrm{~mJ}$ requires caution when using it as an engine fuel. Its laminar flame speed, at stoichiometric conditions, is approximately 5 times faster than the one of gasoline or methane. As the wide flammability limits ranging from 4 to $75 \mathrm{vol} \%$ of $\mathrm{H} 2$ in air allow H2ICEs to be operated with substantial dilution (excess air or EGR), laminar flame speed and flame stability can vary largely, and consequently are important parameters that must be considered. The same properties that make $\mathrm{H} 2$ such a fascinating fuel for ICEs also account for peculiar combustion events. The wide flammability limits together with the low ignition energy required and the high flame speeds could lead to undesired combustion phenomena such as autoignition and backfiring. The latter is limited to port fuel injection (PFI) operation and can be avoided with DI operation, as adopted in the modern H2ICEs. The correlation between mixture quality and NOx - the only relevant emission component in H2ICEs - is well documented in the literature. At fuel-to-air equivalence ratios $(\phi)$ of less than $0.5(\lambda>2)$, the engine operates without generating NOx emissions; increasing $\phi$ beyond this threshold results in an increase of NOx emissions peaking around $\phi \sim 0.75$ and a slight decrease approaching stoichiometric mixtures. It has been demonstrated [15] that the use of a multiple injection strategy in H2-DI ICEs is an effective measure to significantly reduce NOx emissions, up to $95 \%$. Further emission reduction could be gained including EGR and water injection as well as aftertreatment concepts like 3-way catalysts as well as lean NOx traps. The emission levels of modern H2ICE vehicles are by far within the most severe standards while overcoming the fuel economy of their conventional-fuel counterparts. Aside from the use as a neat fuel, H2 is also considered as a combustion enhancer and blending agent with gaseous fuels or in bi- 
fuel operated ICEs, with both gasoline and diesel-like fuels. A $15 \%$ increase of power/density in H2-doped DI ICEs compared to gasoline-fueled units has also been demonstrated [16], and extrapolations from single-cylinder engine efficiency data suggest that a brake thermal efficiency of $45 \%$ is achievable. In the design and optimization of $\mathrm{H} 2-$ doped ICEs, 3D-CFD can be a very promising tool given its ability to span a wide range of technical solutions with reduced times and costs. In the simulation of the combustion phenomena in spark-ignition (SI) engines, flamelet combustion models are largely used by the user community. Despite several flamelet models are available, all of them require laminar flame speed (LFS) as an input to properly estimate the turbulent burn rate. In this work, a TRF surrogate mixed with H2 is used, suitable for representing gasoline-hydrogen blends up to $95 \% \mathrm{~mol}$ of hydrogen. LFS of the blend is provided as an input using a linear mixing rule of the laminar velocity of the two components. In this study, an H2 LFS correlation is derived at typical full-load conditions of GDI engines based on chemical kinetics simulation results, carried out in DARSv4.30 licensed by Siemens DISW, and the reaction mechanisms developed by $[17,18]$. Then, using the aforementioned linear mixing rule, it is combined with a TRF LFS correlation previously developed by the authors in [1921]. Results are implemented in a 3D-CFD software to correctly reproduce the different combustion phenomena based on the mole fraction of $\mathrm{H} 2$ in the blend. The outcomes show how the addition of $\mathrm{H} 2$ in conventional-fuels ICEs leads to a higher power ratio with low emissions and higher fuel economy.

\section{3D-CFD Domain}

A simplified engine geometry, yet fully representative of currently made DISI units, is adopted in this study. The engine is based on a Ford Motor Company unit, simplified to gain stability and to reduce the complexity of the $3 \mathrm{D}$ model. It is a 4-valves pent-roof engine featuring a wall-guided gasoline direct injection system. A Detailed list of engine specifications and operating point is reported in Table 1.

Table 1 - Detailed Engine Specifications

\begin{tabular}{ll}
\hline Parameter & Specification \\
\hline Displacement Volume & $402.0 \mathrm{cc}$ \\
Bore & $80 \mathrm{~mm}$ \\
Stroke & $80 \mathrm{~mm}$ \\
Connecting Rod Length & $139.0 \mathrm{~mm}$ \\
Compression Ratio & $9.0: 1$ \\
Engine Speed & $6500 \mathrm{Rpm}$ \\
Fuel/Air Equivalence Ratio & 1.0 \\
Fuel & TRF-H2 blends $(0.0,50.0,70.0,95.0 \% \mathrm{~mol}$ of H2) \\
Intake Pressure & $1.80 \mathrm{bar}$ \\
Intake Temperature & $46.85{ }^{\circ} \mathrm{C}$ \\
\hline
\end{tabular}

Constant pressures and temperatures representative of a full-load operation are imposed at the intake inlet and exhaust outlet: a value of $1.8 \mathrm{bar}$ is set as inlet pressure at $320 \mathrm{~K}$, while a backpressure of $2.0 \mathrm{bar}$ and a temperature of $950 \mathrm{~K}$ is imposed at the exhaust outlet. Fuel injection is replaced by a premixed mixture of air and fuel. Four different H2/TRF blends are tested. The TRF part is a mixture of iso-octane, n-heptane, and toluene purposely formulated to represent a ULG95 "average gasoline", according to the EN228 specification. The blends differ by the $\mathrm{H} 2$ mole fraction they contain, respectively $0 \%, 30 \%, 50 \%$, and $95 \%$. Further details can be found in Table 2 . 
Table 2 - Blend Compositions

\begin{tabular}{llcc}
\hline Blend & \multicolumn{1}{c}{ Components } & Mole Fraction & Mass Fraction \\
\hline \multirow{3}{*}{ Pure TRF } & H2 & 0.0000 & 0.0000 \\
& iso-C8H18 & 0.4094 & 0.4571 \\
& C7H16 & 0.1391 & 0.1363 \\
& C7H8 & 0.4515 & 0.4067 \\
\hline \multirow{5}{*}{$50 \% \mathrm{H} 2-50 \%$ TRF } & H2 & 0.5000 & 0.0193 \\
& iso-C8H18 & 0.2047 & 0.4483 \\
& C7H16 & 0.0696 & 0.1336 \\
& C7H8 & 0.2258 & 0.3988 \\
\hline \multirow{3}{*}{$70 \% \mathrm{H} 2-30 \% \mathrm{TRF}$} & H2 & 0.7000 & 0.0440 \\
& iso-C8H18 & 0.1228 & 0.4370 \\
& C7H16 & 0.0417 & 0.1303 \\
& C7H8 & 0.1355 & 0.3888 \\
\hline \multirow{3}{*}{$95 \% \mathrm{H} 2-5 \%$ TRF } & H2 & 0.9500 & 0.2724 \\
& iso-C8H18 & 0.0205 & 0.3326 \\
& C7H16 & 0.0070 & 0.0991 \\
& C7H8 & 0.0226 & 0.2959 \\
\hline
\end{tabular}

\section{Numerical Setup}

In this study, a RANS approach to turbulence is adopted for the simulation of the combustion behavior by using the commercial CFD-3D software SimCenter STAR-CCM+ v2021.1 licensed by Siemens DISW. RANS is preferred to other more refined techniques such as DES [22-24] or LES [25-28] since focus is made at present on the average engine performance, without claiming to cover phenomena such as CoV [29], knock [30-32] or misfire [33].

\subsection{Computational Grid}

The meshing tool uses a cell trimming process coupled with a dedicated prismatic mesher for the near-wall grid. Mesh motion is handled by a morphing / remapping technique. Whenever cell quality drops below user-editable quality metrics, a new mesh is generated and results are conservatively interpolated onto the new grid.

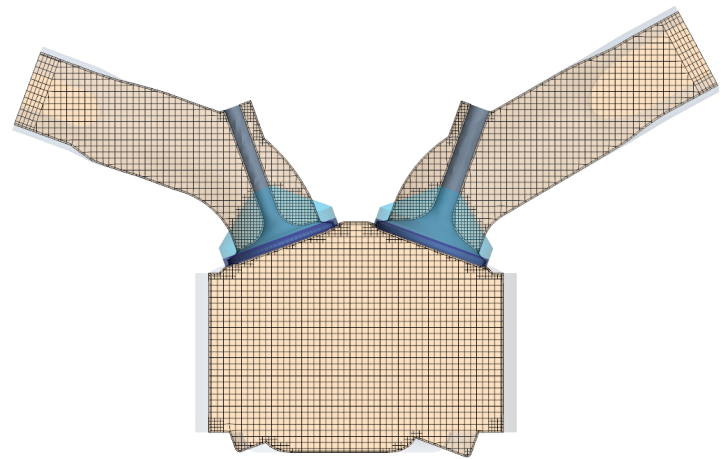

a)

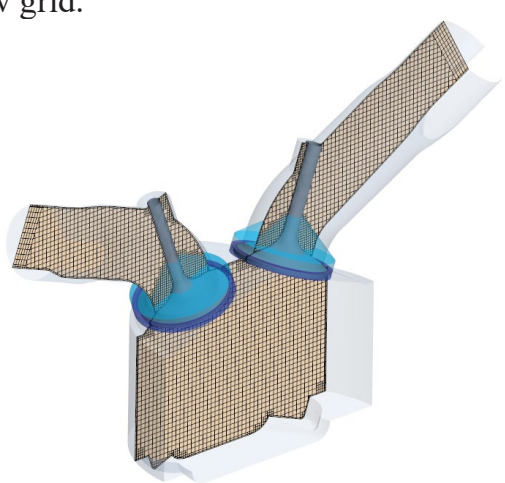

b)

Figure 1 - Computational grid onto Y valves section plane, with CVs highlighted in different colors.

The in-cylinder core grid spacing is equal to $1.5 \mathrm{~mm}$, with fixed and moving adaptive control volumes (CVs) to reduce local cell size down to $0.375 \mathrm{~mm}$. In particular, crank angle-dependent control volumes are activated to handle valve openings and closures. The near-wall grid all over the domain is composed of a single layer with a near-wall thickness 
equal to $0.35 \mathrm{~mm}$. The mesh, visible in Figure 1, is designed to run multiple setups with limited computational resources. The maximum cell count is around 170.000 cells at bottom dead center (BDC), and 100.000 at top dead center (TDC).

\subsection{Physical Models}

Time is solved by the PISO algorithm. A monotone advection and reconstruction scheme (MARS) is used for temporal and spatial discretization. Turbulence is modeled using the Renormalization Group (RNG) K-Epsilon in combination with the High-y+ wall treatment model. The Ideal Gas equation of state is employed to compute the density and its derivatives as a function of temperature and pressure. Sutherland's law is used for the Dynamic Viscosity, while the Specific Heat is computed using a Mass-Weighted Mixture method. Wall heat transfer is modelled using the GruMo-UniMORE thermal wall function [34-37]. The ECFM-3Z model is adopted for the simulation of the combustion phenomena, coupled with two different laminar flame speed correlations.

\subsubsection{Laminar Flame Speed Correlation: Metghalchi and Keck versus GruMoLFSFit}

Modeling flame propagation is essential to provide reliable results. ICEs combustion occurs mostly under the flamelet combustion regime: the reaction zone is localized and turbulence interacts with the flame via corrugation of the reaction zone. Turbulent flames in this regime can be modeled as a thickened flame brush, i.e. the turbulent flame is modeled as a thickened laminar flame. Therefore, an accurate input for LFS is essential. The default laminar flame speed is given by the Metgalchi and Keck correlation as in Eq. 1 [38]:

$$
s_{\mathrm{L}}=s_{l 0}\left(\frac{T_{u}}{T_{0}}\right)^{\alpha} \cdot\left(\frac{p}{p_{0}}\right)^{\beta} \cdot \max \left[1-U_{\text {lam } 1} X_{\text {res }}, \exp \left(U_{\text {lam } 2} X_{\text {res }}\right)\right]
$$

where:

- $s_{l 0}$ is the reference laminar flame speed;

- $\alpha$ e $\beta$ are functions of local $\phi$, and two different formulations for $\beta$ are implemented to cover $p / p_{\text {ref }}$ below and over $p_{\text {transl }}$, being $p_{\text {transl }}$ the normalized transitional pressure value for pressure scaling;

- $\quad \mathrm{p}$ is pressure, $\mathrm{T}$ is temperature, and the subscripts 0 and $\mathrm{u}$ denote reference and unburnt gas properties, respectively;

- $X_{\text {res }}$ is the mole fraction of the residual gas.

- $\quad U_{l a m 1}$ and $U_{l a m 2}$ are the first and second coefficients for EGR respectively.

The reference laminar speed $s_{l 0}$ is a weak function of fuel type and it is fit by a secondorder polynomial of the following form, Eq. 2:

$$
s_{l 0}=B_{m}+B_{2}\left(\phi-\phi_{m}\right)^{2}
$$

where coefficients $\phi_{m}, B_{m}$ and $B_{2}$ are reported in the literature for methanol, propane, and iso-octane. Metghalchi and Keck claim that their LFS is within $10 \%$ of the measured data in the operative range of $0.4 \cdot 10^{6} \leq p \leq 5 \cdot 10^{6} \mathrm{~Pa}, 300 \leq T \leq 700 \mathrm{~K}$, and $0.8 \leq$ $\phi \leq 1.5$.

Following the rationale in $[39,40]$, the in-house developed correlation expresses the LFS $\left(S_{\mathrm{L}}\right)$ as a function of the thermodynamic state and mixture quality (e.g., $\left.\Phi\right)$ as reported in Eq. 3. The fitting coefficients for the H2 LFS are reported in Table 3 along with the reference conditions and range of validity. 


$$
s_{\mathrm{L}}(\phi)=\sum_{\mathrm{i}=1}^{5} \mathrm{a}_{\mathrm{i}} \cdot(\ln (\phi))^{\mathrm{i}} \cdot\left(\frac{T_{\mathrm{u}}}{T_{\text {ref }}}\right)^{\left(\sum_{\mathrm{i}=1}^{5} \mathrm{~b}_{\mathrm{i}} \cdot(\ln (\phi))^{\mathrm{i}}\right)} \cdot\left(\frac{p}{p_{\text {ref }}}\right)^{\left(\sum_{\mathrm{i}=1}^{5} \mathrm{c}_{\mathrm{i}} \cdot(\ln (\phi))^{\mathrm{i}}\right)}
$$

Table 3 - Fitting coefficients, reference pressure and temperature, and range of validity laminar flame speed correlation for H2 (Eq. 3).

\section{FIT COEFFICIENTS}

\begin{tabular}{|c|c|c|c|c|}
\hline & $\mathbf{a}_{\mathbf{i}}$ & $\mathbf{b}_{\mathrm{i}}$ & $\mathbf{c}_{\mathbf{i}}$ & Reference Conditions \\
\hline 0 & 579.410304493307 & 3.08496586863348 & -0.662375482056093 & $T_{\text {ref }} \quad 850 \mathrm{~K}$ \\
\hline 1 & 1126.343332515420 & -2.38624134397731 & 0.740611383386044 & $8 \cdot 10^{6} \mathrm{~Pa}$ \\
\hline 2 & 419.543837792955 & -1.72046449606166 & 1.038324743527740 & \multirow{2}{*}{$\begin{array}{c}\text { Validity Range } \\
0.4<\Phi<1.0\end{array}$} \\
\hline 3 & -807.618181133741 & -1.05803043959888 & 0.767945985221820 & \\
\hline 4 & -1086.552792428860 & 6.76986526585950 & -1.403901570518590 & \multirow{2}{*}{$\begin{array}{c}600 \mathrm{~K}<T_{\mathrm{u}}<1075 \mathrm{~K} \\
3 \cdot 10^{5} \mathrm{~Pa}<p<1.3 \cdot 10^{7} \mathrm{~Pa}\end{array}$} \\
\hline 5 & -435.246230176884 & 5.11161722589838 & -1.575252787580020 & \\
\hline
\end{tabular}

The percentage errors for the resulting $\mathrm{H} 2$ fitted correlation $s_{\mathrm{L}, \text { fit }}$ with respect to the chemical kinetics simulations $S_{\mathrm{L}, \mathrm{sim}}$ are reported in Figure over a wide range of pressures at stoichiometric condition. For each pressure level, three temperatures are considered with a shift of $\pm 100 \mathrm{~K}$ from the central value. As for the TRF LFS, the correlation developed in [21] is adopted. It is worth to emphasize that the validity range of the correlation is much larger than the one of the Metghalchi and Keck correlation, i.e. covering states which are easily reached by the operating conditions of current production ICEs.

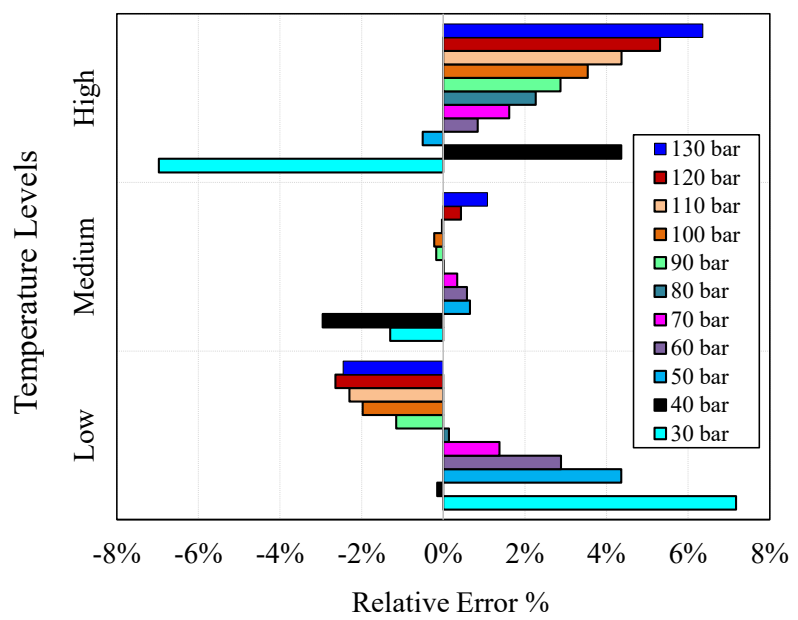

Figure 2 - Relative percentage fitting error (GruMo $s_{l, f i t}$ Vs. $s_{l, s i m}$ ) at stoichiometric conditions

Finally, a mixing rule is used to combine the two correlations into the final CFD input. A simple linear by mass fraction rule is used, see Eq. 4 :

$$
s_{\mathrm{L}, \mathrm{BLEND}}(\Phi)=Y_{\mathrm{TRF}}^{\mathrm{BLEND}} \cdot s_{\mathrm{L}, \mathrm{TRF}}(\Phi)+Y_{\mathrm{H}_{2}}^{\mathrm{BLEND}} \cdot s_{\mathrm{L}, \mathrm{H}_{2}}(\Phi)
$$

Figure 3 shows a comparison between the Metghalchi and Keck correlation and the GruMo LFS fit for Pure-TRF. Lower LFS values are computed using our in-house correlation, 
possibly related to the different conditions in which the fit is validated. Besides the observed differences, it is worth to remark that Metghalchi and Keck correlation is not suitable for $\mathrm{H} 2$ combustion, and an alternative correlation to compute the final LFS of the hydrogen-doped fuel should be chosen.

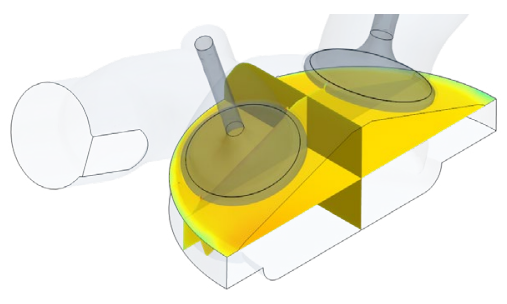

(a)

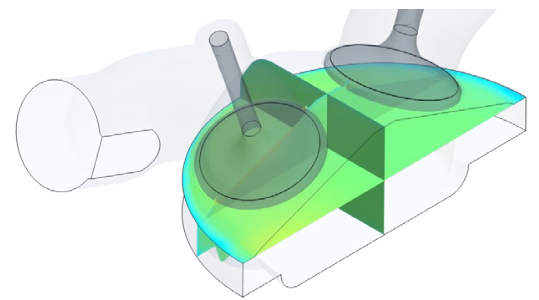

(b)

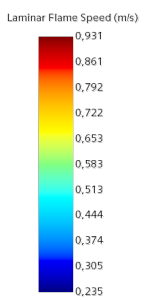

Figure 3 - Laminar Flame Speed pre-spark (689.0 CA deg), a) Metghalchi \& Keck, b) GruMo LFS Fit

A simple energy deposition model is chosen to take care of the ignition process. The simulations share the same combustion model settings. Spark time is set to $690.0 \mathrm{CA}$ deg, for the blend with $\mathrm{H} 2$ content equal to $0 \%$ mol, while increasing the mole fraction of $\mathrm{H} 2$ it is adjusted to achieve reasonably equal phasing of $50 \%$ of mass fraction burnt (MFB).

\section{Results}

A full engine cycle is simulated starting from 80CA degrees After firing TDC (AfTDC). For the sake of brevity, the present analysis focuses on the range from 690CA deg to end of the engine cycle, i.e. $800 \mathrm{CA}$ deg. As a matter of fact, by excluding the fuel injection process, and thus charge cooling due to evaporation and subsequent mixing, differences are limited to changes in the physical properties of the inducted mixture. A first comparison is made between the GruMo LFS correlation and the Metghalchi \& Keck correlation in the TRF-only case. Observing the in-cylinder pressure traces and the combustion indicators in Figure 4 a) and b), it is possible to see a slow-down of the first portion of the combustion process using the GruMo LFS correlation, followed by a steeper pressure rise, which in turn leads to a higher pressure peak.

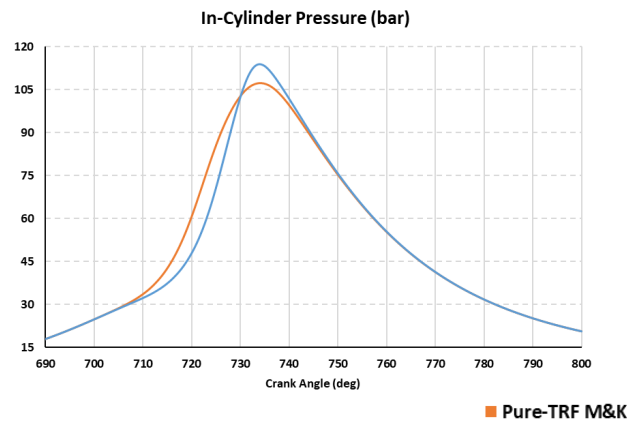

(a)

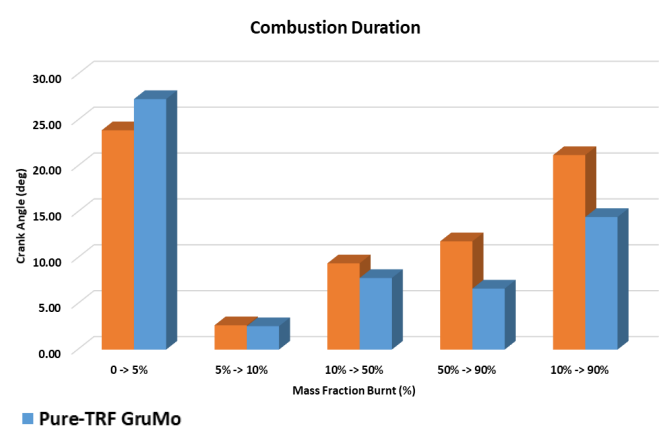

(b)

Figure 4 - In-cylinder pressure traces and combustion phasing of the Pure-TRF simulation with Metghalchi \& Keck (Pure-TRF M\&K) and GruMo LFS correlation (Pure-TRF GruMo)

An increase in the Indicated Mean Effective Pressure (IMEP) is found by adopting the inhouse LFS correlation; values are listed in Table 4. 
Table 4 - Metghalchi \& Keck vs. GruMo LFS correlation power-output outcomes

\begin{tabular}{lcccc}
\hline & IMEP (bar) & AIMEP (\%) & Qth (kJ) & Qcomb (kJ) (690 -> 790 CAdeg) \\
\hline Pure TRF M\&K & 15.999 & $/$ & 1.1181 & 1.0761 \\
Pure TRF GruMo & 16.150 & $+0.95 \%$ & 1.1181 & 1.0795 \\
\hline
\end{tabular}

The introduction of $\mathrm{H} 2$ in the inducted fuel on equal inlet conditions, leads to lower energy available in the combustion chamber, $\mathrm{Q}_{\mathrm{th}}$, primarily due to the lower density of $\mathrm{H} 2$ compared to that of TRF, as shown in Figure $6 \mathrm{~b}$ ). Figure 5 a) shows the in-cylinder pressure traces resulting by the different tested fuels. A positive trend increasing the $\mathrm{H} 2$ content is found in terms of combustion history until a cap is reached: in fact, increasing the $\mathrm{H} 2$ content over $70 \%$ mol the available $\mathrm{Q}_{\text {th }}$ is too low to reach the target pressure peak. Looking at Figure $5 \mathrm{~b}$ ) it is possible to see the phasing of the combustion process. For this set of simulations, the SA of the Pure-TRF is kept at the original value, i.e. 690 CAdeg, while the SA of the others is moved forward to meet nearly equal phasing of $50 \%$ of MFB. Increasing the $\mathrm{H} 2$ content $\mathrm{SA}$ is moved forward by $6.5,11.5$, and 23.4 CAdeg respectively for the $50 \%, 70 \%$ and $95 \%$ of $\mathrm{H} 2$ content. IMEP is lower than the pure TRF case for all the $\mathrm{H} 2$-doped simulations. This is due to the lower $\mathrm{Q}_{\mathrm{th}}$ in the combustion chamber. However, a remarkable reduction of Brake Specific Fuel Consumption (BSFC) is found for increasing H2 content.

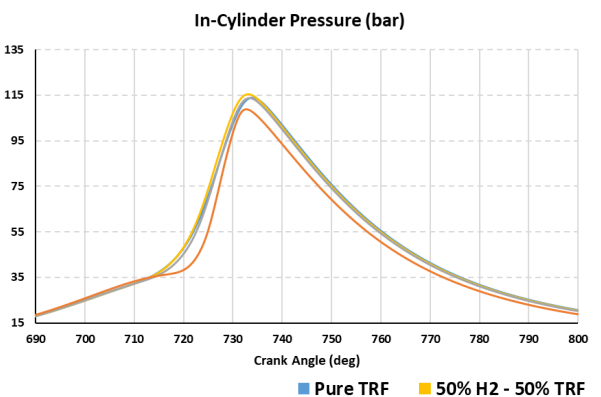

(a)

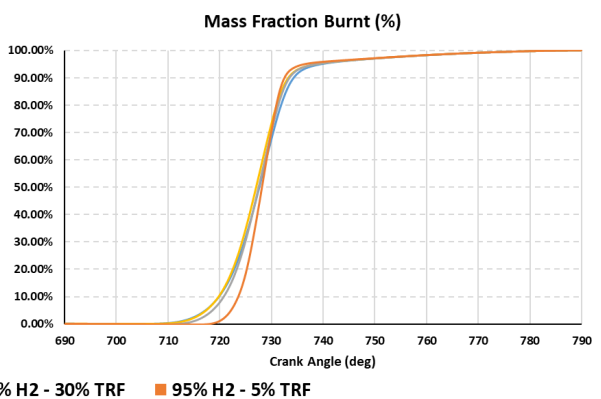

(b)

Figure 5 - In-Cylinder pressure and MFB traces of the different blends, on equal boundary conditions

With a $50 \%$ mol of $\mathrm{H} 2$ in the fuel, a reduction of $\mathrm{Q}_{\text {th }}$ equal to $1.05 \%$ is found which leads to a reduction of $1.01 \%$ of IMEP and a BSFC gain of $3.37 \%$. Moving to $70 \%$ mole fraction of $\mathrm{H} 2$, the loss in $\mathrm{Q}_{\text {th }}$ increases to $2.38 \%$ with a decrease of IMPE of $2.89 \%$ and a gain in BSFC equal to $6.79 \%$. The extreme case of $95 \% \mathrm{H} 2$ leads to a BSFC saving of over $30 \%$, at the cost of a reduction in IMEP, and therefore performance, of almost $15 \%$. Results depicted in Figure 6, are listed in the following table, Table 5.

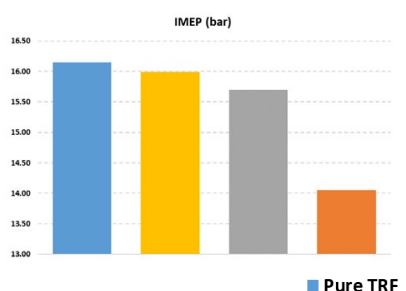

(a)

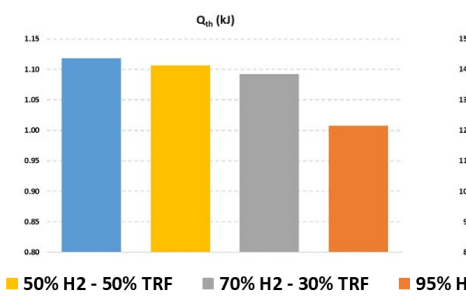

(b)

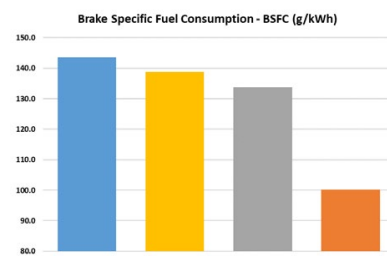

(c)

Figure 6 - IMEP, Qth, and BSFC for the different blends on equal inlet conditions. 
Table 5 - IMEP, Qth, and BSFC values reached with the different blends under the same inlet conditions.

\begin{tabular}{lccccc}
\hline & Spark Time (CA deg) & IMEP (bar) & Qth (kJ) & BSFC (g/kWh) & BSFC Reduction \\
\hline Pure TRF & 690.0 & 16.150 & 1.1181 & 143.5819 & $/$ \\
$50 \%$ H2 - 50\% TRF & 696.5 & 15.989 & 1.1065 & 138.7446 & $3.37 \%$ \\
$70 \%$ H2 - 30\% TRF & 701.5 & 15.697 & 1.0922 & 133.8383 & $6.79 \%$ \\
$95 \%$ H2 - 5\% TRF & 713.4 & 14.053 & 1.0076 & 100.1743 & $30.23 \%$ \\
\hline
\end{tabular}

To evaluate the potential BSFC gain on equal IMEP, inlet conditions are adjusted to counterbalance the lower density of $\mathrm{H} 2$. Thus, intake pressure is progressively increased in the H2-doped simulations. The inlet temperature, as well as the overall $\phi$, are kept unaltered. With these updated inlet settings, all the simulations share almost equal $\mathrm{Q}_{\mathrm{th}}$, within a range of $+0.09-+1.32 \%$. For the sake of clarity, all the values are listed in Table 6. SA is again adjusted to meet nearly equal phasing of $50 \% \mathrm{MFB}$. A further increase in SA with respect to the previous cases is needed. As depicted in Figure 7, all the simulations reach $50 \%$ of MFB within a range of -0.50 and +0.50 CAdeg.

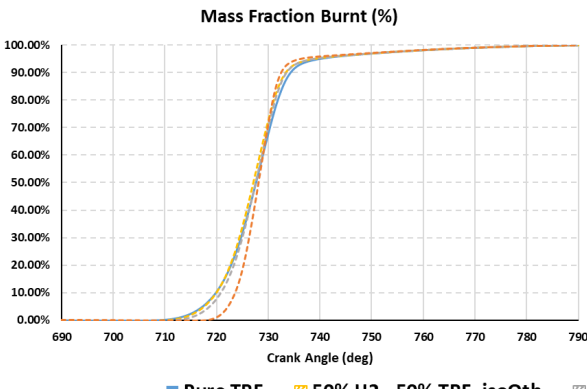

Pure TRF 0 50\% H2 - 50\% TRF_isoQth (a)

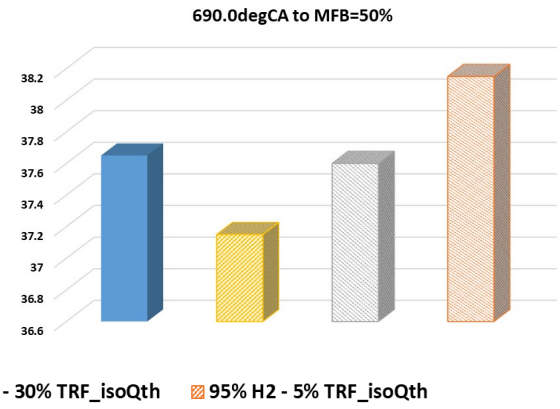

(b)

Figure 7 - MFB plot for the different tested blends on equal $\mathrm{Q}_{\mathrm{th}}$.

The increased $\mathrm{Q}_{\mathrm{th}}$, as expected, leads to progressive increase of pressure peak for increasing $\mathrm{H} 2$ content. Now, the available energy is the same for the different simulations, and the increase of $\mathrm{H} 2$ directly impacts on the power output of the engine. In-cylinder pressure traces, as well as the apparent heat release ones (AHRR), are shown in Figure 8.

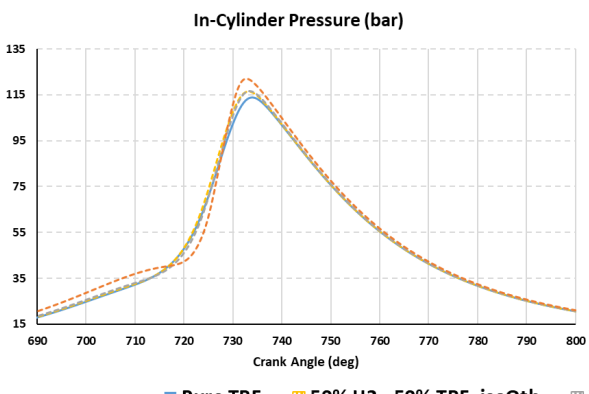

Pure TRF

(a)

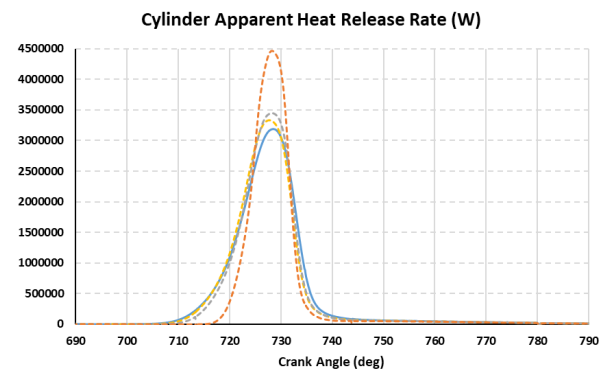

(b)

Figure 8 - In-cylinder pressure and AHRR traces for the different tested blends on equal $Q_{\text {th. }}$

Comparable IMEP values are now found, with a reduction in BSFC which reaches slightly more than $30 \%$ for the $95 \% \mathrm{H} 2$ case with respect to the pure-TRF counterpart. Values are listed in Table 6 for the sake of clarity. 
Table 6 - IMEP, Qth, and BSFC values reached with the different tested blends, by introducing almost the same $\mathrm{Q}_{\text {th }}$ in the combustion chamber.

\begin{tabular}{lccccc}
\hline & Spark Time (CA deg) & IMEP (bar) & Qth $_{\text {tkJ) }}$ & BSFC (g/kWh) & BSFC Reduction \\
\hline Pure TRF & 690.0 & 16.150 & 1.1181 & 143.5819 & $/$ \\
$50 \%$ H2 - 50\% TRF isoQth & 697.0 & 16.171 & 1.1192 & 138.7609 & $3.36 \%$ \\
$70 \%$ H2 - 30\% TRF isoQth & 701.9 & 16.122 & 1.1214 & 133.7946 & $6.82 \%$ \\
95\% H2 - 5\% TRF isoQth & 713.7 & 15.841 & 1.1331 & 99.9388 & $30.40 \%$ \\
\hline
\end{tabular}

Results from this preliminary analysis seem to suggest that doping the fuel with $\mathrm{H} 2$ and operating the engine on equal available energy, a gain in performance can be achieved. Even more promising, a remarkable reduction in tailpipe emissions due to the reduction of carbon-content of the fuel is found. In fact, progressively lower $\mathrm{CO}, \mathrm{CO}_{2}$ and $\mathrm{NO}$ masses are found in the cylinder at EVO, as reported in Table 7.

Table 7 - Tailpipe emissions for the different blendson equal $\mathrm{Q}_{\text {th. }}$.

\begin{tabular}{lcccccc}
\hline & $\begin{array}{c}\text { CO mass } \\
(\mathbf{m g})\end{array}$ & $\begin{array}{c}\text { CO } \\
\text { Reduction }\end{array}$ & $\begin{array}{c}\text { CO2 mass } \\
(\mathbf{m g})\end{array}$ & $\begin{array}{c}\text { CO2 } \\
\text { Reduction }\end{array}$ & $\begin{array}{c}\text { NO mass } \\
(\mathbf{m g})\end{array}$ & $\begin{array}{c}\text { NO } \\
\text { Reduction }\end{array}$ \\
\hline Pure TRF & 1.55 & $/$ & 83.99 & $/$ & 1.24 & $/$ \\
$50 \% \mathrm{H} 2-50 \% \mathrm{TRF}$ isoQ & 1.49 & $3.43 \%$ & 79.67 & $5.13 \%$ & 1.22 & $2.08 \%$ \\
$70 \% \mathrm{H} 2-30 \% \mathrm{TRF}$ isoQth & 1.44 & $6.61 \%$ & 74.60 & $11.18 \%$ & 1.18 & $4.92 \%$ \\
$95 \% \mathrm{H} 2-5 \% \mathrm{TRF}$ isoQ & 0.98 & $36.40 \%$ & 41.39 & $50.71 \%$ & 0.96 & $23.19 \%$ \\
\hline
\end{tabular}

In particular, the $95 \%$ mol case shows a massive reduction of around $23 \%$ in $\mathrm{NO}, 36 \%$ in $\mathrm{CO}$ and $50 \%$ in $\mathrm{CO} 2$ mass.

\section{Summary/Conclusions}

Four different TRF-H2 blends are formulated, and their combustion behavior is studied using a 3D-CFD. To this aim, an ad-hoc LFS correlation is developed, following a previously presented methodology. The different blends are compared both on equal inlet conditions and on equal energy availability. On equal inlet conditions, a higher mole fraction of $\mathrm{H} 2$ in the fuel results in a moderate improvement in BSFC up to a cap fraction, above which the loss in performance becomes critical. Better results are achieved by changing the inlet conditions to reach equal available energy $\mathrm{Q}_{\text {th }}$ in the combustion chamber. With an average intake pressure increase of nearly $11 \%$, the power-output can be kept equal to the original gasoline-only case. Such performance is achieved with a reduction of almost $32 \%$ in fuel mass per engine cycle and with a drop of $\mathrm{CO}, \mathrm{CO}_{2}$, and $\mathrm{NO}$ massed at EVO. While not addressed in this preliminary study, the addition of $\mathrm{H} 2$ is expected to speed up combustion through the increase of LFS. This may help reducing combustion $\mathrm{CoV}$ and sporadic events such as misfire and knock.

The activity will be extended to cover pure $\mathrm{H} 2$ fueling as well as to move from premixed inlet charge to a more challenging direct $\mathrm{H} 2$ injection scenario.

\section{Reference}

1 E. Commission. Secretariat-General EUR-Lex - 52019DC0640, (2019).

2 E. Parliament. Council of the European Union EUR-Lex - 32009L0028, (2009). 
3 E. Commission. Directorate-General for Climate Action EUR-Lex 52017PC0676, (2017).

4 E. Parliament. Council of the European Union EUR-Lex - 32018L2001, (2018).

5 L. Tao, E. C. D. Tan, R. McCormick, M. Zhang, A. Aden, X. He, and B. T. Zigler. Biofuels, Bioproducts and Biorefining 8, no. 1 30-48 (2013). https://doi.org/10.1002/bbb.1431

6 L. G. Pereira, M. O. S. Dias, A. P. Mariano, R. Maciel Filho, and A. Bonomi. Applied Energy 160 120-31 (2015). https://doi.org/10.1016/i.apenergy.2015.09.063 A. Irimescu, S. S. Merola, S. Di Iorio, and B. M. Vaglieco. Fuel 216 121-41 (2018). https://doi.org/10.1016/j.fuel.2017.11.116

8 S. Di lorio, F. Catapano, P. Sementa, B. M. Vaglieco, S. Florio, E. Rebesco, P. Scorletti, and D. Terna. SAE Technical Paper Series, SAE International, (2014). https://doi.org/10.4271/2014-32-0038

9 S. M. Sarathy, A. Farooq, and G. T. Kalghatgi. Progress in Energy and Combustion Science 65 67-108 (2018). https://doi.org/10.1016/i.pecs.2017.09.004

$10 \mathrm{~S}$. Verhelst, and T. Wallner. Progress in Energy and Combustion Science 35, no. 6 490-527 (2009). https://doi.org/10.1016/i.pecs.2009.08.001

11 M. Shelef, and C. A. Kukkonen. Progress in Energy and Combustion Science 20, no. 2 139-48 (1994). https://doi.org/10.1016/03601285(94)90008-6

12 A. d'Adamo, M. Riccardi, M. Borghi, and S. Fontanesi. Processes 9, no. 3 564 (2021). https://doi.org/10.3390/pr9030564

13 M. Riccardi, A. d'Adamo, A. Vaini, M. Romagnoli, M. Borghi, and S. Fontanesi. E3S Web Conf. 19705004 (2020). https://doi.org/10.1051/e3sconf/202019705004

14 A. D'Adamo, M. Riccardi, C. Locci, M. Romagnoli, and S. Fontanesi. SAE Technical Paper Series, SAE International, (2020). https://doi.org/10.4271/2020-24-0016

15 S. D. Zambalov, I. A. Yakovlev, and A. S. Maznoy. Energy Conversion and Management 220113097 (2020).

https://doi.org/10.1016/i.enconman.2020.113097

16 S. Verhelst, P. Maesschalck, N. Rombaut, and R. Sierens. International Journal of Hydrogen Energy 34, no. 5 2504-10 (2009). https://doi.org/10.1016/j.ijhydene.2009.01.009

17 E. Ranzi, A. Frassoldati, R. Grana, A. Cuoci, T. Faravelli, A. P. Kelley, and C. K. Law. Progress in Energy and Combustion Science 38, no. 4 468501 (2012). https://doi.org/10.1016/j.pecs.2012.03.004 E. Ranzi, C. Cavallotti, A. Cuoci, A. Frassoldati, M. Pelucchi, and T. Faravelli. Combustion and Flame 162, no. 5 1679-91 (2015). https://doi.org/10.1016/j.combustflame.2014.11.030

19 M. Del Pecchia, S. Breda, A. D'Adamo, S. Fontanesi, A. Irimescu, and S. Merola. SAE International Journal of Engines 11, no. 6 715-41 (2018). https://doi.org/10.4271/2018-01-0174

20 M. Del Pecchia, and S. Fontanesi. Fuel 279118337 (2020). https://doi.org/10.1016/i.fuel.2020.118337

21 M. Del Pecchia, V. Pessina, F. Berni, A. d'Adamo, and S. Fontanesi. Fuel 264116741 (2020). https://doi.org/10.1016/i.fuel.2019.116741 
22 V. K. Krastev, A. d'Adamo, F. Berni, and S. Fontanesi. International Journal of Engine Research 21, no. 4 632-48 (2019).

https://doi.org/10.1177/1468087419851905

23 C. lacovano, A. d'Adamo, S. Fontanesi, G. Di Ilio, and V. K. Krastev. International Journal of Engine Research 0, no. 01468087420931712 (2020). https://doi.org/10.1177/1468087420931712

24 V. K. Krastev, G. Di Ilio, C. lacovano, A. d'Adamo, and S. Fontanesi. E3S Web Conf. 19706021 (2020).

https://doi.org/10.1051/e3sconf/202019706021

25 F. Rulli, A. Barbato, S. Fontanesi, and A. d'Adamo. International Journal of Engine Research 22, no. 5 1440-56 (2020). https://doi.org/10.1177/1468087419896469

26 F. Rulli, S. Fontanesi, A. d'Adamo, and F. Berni. International Journal of Engine Research 22, no. 1 222-42 (2019). https://doi.org/10.1177/1468087419836178

27 C. lacovano, Y. Zeng, M. Anbarasu, S. Fontanesi, and A. D'Adamo. SAE Technical Paper Series, SAE International, (2021). https://doi.org/10.4271/2021-01-0399

28 Y. Shekhawat, D. C. Haworth, A. d'Adamo, F. Berni, S. Fontanesi, P. Schiffmann, D. L. Reuss, and V. Sick. Oil \& Gas Science and Technology Rev. IFP Energies nouvelles 72, no. 532 (2017).

https://doi.org/10.2516/ogst/2017028

29 S. Fontanesi, S. Paltrinieri, A. Tiberi, and A. D'Adamo. SAE Technical Paper Series, SAE International, (2013). https://doi.org/10.4271/2013-011080

30 S. Breda, A. D'Adamo, S. Fontanesi, N. Giovannoni, F. Testa, A. Irimescu, S. Merola, C. Tornatore, and G. Valentino. SAE International Journal of Engines 9, no. 1 641-56 (2016). https://doi.org/10.4271/2016-01-0601

31 A. D'Adamo, S. Breda, S. laccarino, F. Berni, S. Fontanesi, B. Zardin, M. Borghi, A. Irimescu, and S. Merola. SAE International Journal of Engines 10, no. 3 722-39 (2017). https://doi.org/10.4271/2017-01-0551

32 S. Fontanesi, G. Cicalese, A. d'Adamo, and G. Cantore. Energy Procedia 45 769-78 (2014). https://doi.org/10.1016/j.egypro.2014.01.082

33 A. d'Adamo, C. lacovano, and S. Fontanesi. Applied Energy 280115949 (2020). https://doi.org/10.1016/j.apenergy.2020.115949

34 F. Berni, and S. Fontanesi. Applied Thermal Engineering 174115320 (2020). https://doi.org/10.1016/j.applthermaleng.2020.115320

35 F. Berni, G. Cicalese, M. Borghi, and S. Fontanesi. Applied Thermal Engineering 190116838 (2021). https://doi.org/10.1016/j.applthermaleng.2021.116838

36 F. Berni, S. Fontanesi, G. Cicalese, and A. D'Adamo. SAE International Journal of Commercial Vehicles 10, no. 2 547-61 (2017).

https://doi.org/10.4271/2017-01-0569

37 S. Fontanesi, G. Cicalese, A. D'Adamo, and G. Pivetti. SAE Technical Paper Series, SAE International, (2011). https://doi.org/10.4271/2011-24$\underline{0132}$

38 M. Metghalchi, and J. C. Keck. Combustion and Flame 48, no. 2 191-210 (1982). https://doi.org/10.1016/0010-2180(82)90127-4

39 S. Breda, A. D'Adamo, S. Fontanesi, F. D'Orrico, A. Irimescu, S. Merola, and N. Giovannoni. SAE International Journal of Fuels and Lubricants 10, no. 1 32-55 (2017). https://doi.org/10.4271/2017-01-0546 
40 M. Del Pecchia, S. Fontanesi, J. Prager, C. Kralj, and H. Lehtiniemi. Applied Energy 280115909 (2020). https://doi.org/10.1016/j.apenergy.2020.115909

\section{Definitions/Abbreviations}

\begin{tabular}{|c|c|}
\hline AfTDC & After Firing Top Dead Center \\
\hline AHRR & Apparent Heat Release \\
\hline BDC & Bottom Dead Center \\
\hline BSFC & Brake Specific Fuel Consumption \\
\hline $\mathrm{CA}$ & Crank Angle \\
\hline CFD & Computational Fluid Dynamics \\
\hline $\mathrm{CoV}$ & Coefficient of Variation \\
\hline $\mathrm{CO}$ & Carbon Monoxide \\
\hline $\mathrm{CO} 2$ & Carbon Dioxide \\
\hline $\mathrm{CV}$ & Control Volume \\
\hline DES & Detached Eddy Simulation \\
\hline DI & Direct-Injection \\
\hline DISI & Direct-Injection Spark-Ignition \\
\hline EGR & Exhaust Gas Recirculation \\
\hline $\mathrm{Eq}$ & Equation \\
\hline EU & European Union \\
\hline EVO & Exhaust Valve Opening \\
\hline GDI & Gasoline Direct Injection \\
\hline GHG & Anthropogenic Greenhouse Gas \\
\hline $\mathrm{HC}$ & Hydrocarbon \\
\hline $\mathrm{H} 2$ & Hydrogen \\
\hline $\mathrm{H} 2 \mathrm{ICE}$ & $\begin{array}{l}\text { Hydrogen-Fueled Internal Combustion } \\
\text { Engine }\end{array}$ \\
\hline ICE & Internal Combustion Engine \\
\hline IMEP & Indicated Mean Effective Pressure \\
\hline LES & Large Eddy Simulation \\
\hline LFS & Laminar Flame Speed \\
\hline LHV & Lower Heating Value \\
\hline MARS & $\begin{array}{l}\text { Monotone Advection and Reconstruction } \\
\text { Scheme }\end{array}$ \\
\hline MFB & Mass Fraction Burnt \\
\hline NOx & Nitrogen Oxides \\
\hline PFI & Port Fuel Injection \\
\hline PISO & Pressure Implicit with Splitting of Operator \\
\hline $\mathrm{PM}$ & Particulate Matter \\
\hline Qth & Theroretical Energy \\
\hline RANS & Reynolds Average Navier Stokes \\
\hline RED & Renewable Energy Directive \\
\hline RNG & Renormalization Group \\
\hline SI & Spark-Ignition \\
\hline
\end{tabular}




\begin{tabular}{|l|l|}
\hline SO2 & Sulphur Dioxide \\
\hline TDC & Top Dead Center \\
\hline TRF & Toluene Reference Fuel \\
\hline ULG95 & "Average Gasoline", EN228 Specification \\
\hline
\end{tabular}

